\title{
Multilayered $\mathrm{MoS}_{2}$ Coated $\mathrm{TiO}_{2}$ Hollow Spheres for Efficient
}

\section{Photodegradation of Phenol under Visible Light Irradiation}

\author{
Jilong Wang ${ }^{\mathrm{a}}$, Bo Wei ${ }^{\mathrm{b}}$, Lingling Xu ${ }^{\mathrm{a}}{ }^{*}, \mathrm{Hong}_{\mathrm{Gao}}{ }^{\mathrm{a}}$, Wenjun Sun ${ }^{\mathrm{a}}$, Jixin Che ${ }^{\mathrm{c}}$, \\ a Key Laboratory of Photonic and Electric Bandgap Materials, Ministry of Education, School of Physics and \\ Electronic Engineering, Harbin Normal University, Harbin, 150025, PR China \\ $b$ Department of Physics, Harbin Institute of Technology, Harbin 150080, PR China \\ $c$ The Aviation University of Air Force, Changchun 130022, PR China
}

Abstract:

Multilayered $\mathrm{MoS}_{2}$ coated hollow $\mathrm{TiO}_{2}$ heterostructures were fabricated by a two-step hydrothermal process using $\mathrm{TiO}_{2}$ hollow spheres as precursors. Compared with pure $\mathrm{TiO}_{2}$, the heterostructures exhibited greatly enhanced visible-light-responsive activity on photodecomposition of colorless phenol, due to the enlargement of visible light absorption and improvement separation efficiency of photogenerated electron-hole pairs. Photocatalytic activity was influenced by the $\mathrm{MoS}_{2} / \mathrm{TiO}_{2}$ ratio and the optimized composition was obtained with high stability during recycling.

Keywords: Semiconductors; Nanocomposites; $\mathrm{TiO}_{2} ; \mathrm{MoS}_{2}$; Photodecomposition; Photocatalysts

\section{Introduction}

The global energy crisis and demand for environmental protection promote the research on semiconductor photocatalysts with kinds of nanostructures. Titanium dioxide $\left(\mathrm{TiO}_{2}\right)$ is widely recognized as the most excellent candidate for commercial photocatalysts, because it shows high photocatalytic property in the degradation of organic compounds and hydrogen production and long-term stability against photo- and chemical corrosion [1,2]. However, its applications are largely hindered by the low quantum efficiency in photocatalytic reactions and ineffective utilization of visible light, which result from its high recombination of photo-generated electron-hole pairs and wide band gap ( $\sim 3.3 \mathrm{eV}$ for the anatase phase). Therefore, it is highly desirable to develop photocatalysts with high catalytic activities under the visible light range. To achieve this goal, the design and growth of $\mathrm{TiO}_{2}$-based heterostructures using a semiconductor with narrow band gap is an effective way to promote the transfer of photo-induced electron and enlarge the light absorption [3-5].

Recently, 2D layered $\mathrm{MoS}_{2}$ has been widely studied for the potential applications in supercapacitors, solar cell and photocatalysis etc. Layered $\mathrm{MoS}_{2}$ has been deposited on $\mathrm{TiO}_{2}$ nanobelts, nanofibers and nanoclusters to enlarge the light absorption and improve the performance of photocatalytic hydrogen generation and photodegradation of hazardous organic pollutants [6-8]. Hollow $\mathrm{TiO}_{2}$ sphere has been reported with superior photocatalytic activity because of the relatively large surface area compared with nanoparticle [7]. In this work, multi-layered $\mathrm{MoS}_{2}$ coated $\mathrm{TiO}_{2}$ hollow spheres were successfully prepared, which exhibits high activity for photodecomposition of colorless phenol.

\section{Experimental}

\section{Preparation of $\mathrm{TiO}_{2} / \mathrm{MoS}_{2}$ heterostructures}

$\mathrm{TiO}_{2}$ hollow sphere was synthesized by a facile hydrothermal method [9-12] and the $\mathrm{TiO}_{2} / \mathrm{MoS}_{2}$ heterostructures were fabricated as follows. Typically, $135 \mathrm{mg}$ of sodium molybdate $\left(\mathrm{Na}_{2} \mathrm{MoO}_{4} \cdot 2 \mathrm{H}_{2} \mathrm{O}\right)$ and $90 \mathrm{mg}$ of thioacetamide $\left(\mathrm{C}_{2} \mathrm{H}_{5} \mathrm{NS}\right)$ were dissolved in $20 \mathrm{~mL}$ of deionized water to form a transparent solution. Then, $30 \mathrm{mg}, 60 \mathrm{mg}, 90 \mathrm{mg}$ and $120 \mathrm{mg}$ of $\mathrm{TiO}_{2}$ hollow spheres were added into the above solution and stirred to get a suspension and the resulted samples were named TM3, TM6, TM9 and TM12, respectively. The whole mixture was transferred into a Teflon-lined stainless steel autoclave and kept at $220{ }^{\circ} \mathrm{C}$ for $24 \mathrm{~h}$ to deposit $\mathrm{MoS}_{2}$ on the surface of $\mathrm{TiO}_{2}$ spheres. The precipitate was collected, washed and finally dried at $60{ }^{\circ} \mathrm{C}$ for $12 \mathrm{~h}$ in a vacuum oven to get the $\mathrm{TiO}_{2} / \mathrm{MoS}_{2}$ heterostructures $[13,14]$.

*Corresponding author: xulingling_hit@163.com; Tel: +86-451-88060349 


\section{Characterization}

The composition and phase purity of $\mathrm{TiO}_{2} / \mathrm{MoS}_{2}$ were analyzed by a Rigaku D/max-2600/PC X-ray diffractometer (XRD) using $\mathrm{Cu}-\mathrm{K} \alpha$ radiation. Sample microstructures were revealed by a Hitachi SU-70 scanning electron microscopy (SEM) and a FEI Tecnai G2 F20 transmission electron microscope (TEM). UV-vis diffuse reflectance spectra (DRS) were obtained by a Shimadzu UV-2500 spectrophotometer with a $\mathrm{BaSO}_{4}$ reflectance standard. Photocatalytic activity was evaluated under visible light irradiation using a $300 \mathrm{~W}$ Xe lamp with a cut off filter $(\lambda \geq 420 \mathrm{~nm})$. The colorless phenol was chosen as a model pollutant to evaluate the photocatalytic activity with a concentration of $10 \mathrm{mg} / \mathrm{L}$. $0.01 \mathrm{~g}$ catalyst was added in the reaction of $60 \mathrm{~mL}$ solution and the concentration change was monitored by a Perkin-Elmer Lambda-35 UV-Vis spectrophotometer at the maximum absorption band (269 nm). The photocurrent was measured by a Chenhua CHI 660E electrochemical system in $0.5 \mathrm{M} \mathrm{Na}_{2} \mathrm{SO}_{4}$ solution using a Pt-calomel electrode.

\section{Results and discussion.}

Fig. 1 presents the $\mathrm{XRD}$ patterns of $\mathrm{TiO}_{2} / \mathrm{MoS}_{2}$ heterostructures and pure $\mathrm{TiO}_{2}$ and $\mathrm{MoS}_{2}$. For pure $\mathrm{TiO}_{2}$, all the detected peaks coincide with the standard anatase phase of $\mathrm{TiO}_{2}$ (JCPDS No. 89-4921). As for the pure $\mathrm{MoS}_{2}$ powder, the diffraction peaks can be clearly assigned to the (003), (101), (104) and (110) planes in the hexagonal phase $\mathrm{MoS}_{2}$ (JCPDS No. 17-0744) [15]. For the $\mathrm{TiO}_{2} / \mathrm{MoS}_{2}$ composites, both phases can be observed and the diffraction peaks intensity of $\mathrm{MoS}_{2}$ tend to be stronger with the increasing content of $\mathrm{MoS}_{2}$. The results show that the $\mathrm{TiO}_{2} / \mathrm{MoS}_{2}$ composites are successfully prepared and the component ratios can be easily controlled by varying the $\mathrm{TiO}_{2}$ adding.

Fig. 2 presents the typical SEM images of pure $\mathrm{TiO}_{2}, \mathrm{MoS}_{2}$ and the $\mathrm{TiO}_{2} / \mathrm{MoS}_{2}$ heterostructures. Pure $\mathrm{TiO}_{2}$ sphere, formed via an ostwald ripening process (Fig. 2a), shows coarse surface, which is made up by many $\mathrm{TiO}_{2}$ nanocrystalline. Pure $\mathrm{MoS}_{2}$ exhibits sheet-like morphology with a slightly bending at the edge (Fig. 2b). After the hydrothermal process with the adding of $30 \mathrm{mg} \mathrm{TiO}$, the $\mathrm{TiO}_{2} / \mathrm{MoS}_{2}$ composite maintains the sphere ball morphology with fluffy $\mathrm{MoS}_{2}$ decorated on surface. The broken sphere covered by $\mathrm{MoS}_{2}$ in Fig. 2c proves its hollow structure. As the quantity of $\mathrm{TiO}_{2}$ increasing, the $\mathrm{TiO}_{2} / \mathrm{MoS}_{2}$ composites kept hollow sphere structure, while the content of $\mathrm{MoS}_{2}$ deposited on the rough surface is gradually reduced in Fig. 2d,e and f. Thus, the ratio of $\mathrm{MoS}_{2}$ deposited on $\mathrm{TiO}_{2}$ can be easily tuned by adjusting the $\mathrm{TiO}_{2}$ content.

To further observe of the heterostructure microstructure, typical TEM images of $\mathrm{TiO}_{2} / \mathrm{MoS}_{2}$ (TM9) are shown in Fig. 3. Obviously, the hollow structure is relative uniform with a diameter about $600 \mathrm{~nm}$ (Fig. 3a). An enlarged view in Fig. $3 \mathrm{~b}$ shows that the thickness of $\mathrm{TiO}_{2} / \mathrm{MoS}_{2}$ shell is no more than $100 \mathrm{~nm}$. Moreover, the hollow structure present high porosity, which would provide with high surface area for the photoreactions. High resolution TEM image in Fig. 3c gives the crystalline structure from the selected rectangle area. The shell displayed two types of clear lattice fringes. The fringes spacing of $0.35 \mathrm{~nm}$ is corresponding to the (101) plane of the anatase $\mathrm{TiO}_{2}$ [16]. On the other hand, the spacing of a few layer $\mathrm{MoS}_{2}$ sheets was observed and measured as $0.75 \mathrm{~nm}$, which is in accordance with the reported value [8]. The selected area electron diffraction (SAED) in Fig. 3d gives the values of R1 and R2 of 0.3510 and $0.2712 \mathrm{~nm}$, respectively. According to the Bragg equation, the calculated d1 and $\mathrm{d} 2$ are $0.3509 \mathrm{~nm}$ for $\mathrm{TiO}_{2}$ (101) and $0.2710 \mathrm{~nm}$ for $\mathrm{MoS}_{2}$ (101), respectively, confirming the formation of $\mathrm{TiO}_{2} / \mathrm{MoS}_{2}$ heterostructure.

The UV-vis DRS are shown in Fig. 4a. The light absorption of $\mathrm{TiO}_{2}$ starts from $380 \mathrm{~nm}$ and the band gap energy is about $3.25 \mathrm{eV}$. With the decreasing of $\mathrm{TiO}_{2}$ adding, the light absorption range of the $\mathrm{TiO}_{2} / \mathrm{MoS}_{2}$ heterostructures is greatly enlarged in the visible range, due to the light absorption of $\mathrm{MoS}_{2}$. Clearly, the ability of light absorption of $\mathrm{TiO}_{2} / \mathrm{MoS}_{2}$ composites is enhanced comparing with pure $\mathrm{TiO}_{2}$. Although the absorption properties of heterostructure are weaker than that of the pure $\mathrm{MoS}_{2}$, the superior photocatalytic performance is obtained for the composite photocatalysts. 
Fig. $4 \mathrm{~b}$ gives the variation of phenol concentration $\left(\mathrm{C} / \mathrm{C}_{0}\right)$ with the photodegradation time over different photocatalysts. All the $\mathrm{TiO}_{2} / \mathrm{MoS}_{2}$ composites exhibit higher activity than that of pure $\mathrm{TiO}_{2}$ and $\mathrm{MoS}_{2}$. With the increasing of $\mathrm{TiO}_{2}$ content, the photocatalytic activity is enhanced at first and then decreased. The TM9 photocatalyst presents the best performance and the phenol was decomposed $78 \%$ after 150 min irradiation. According to the Langmuir-Hinshelwood (L-H) kinetics model, the apparent pseudo-first-order rate constant $\left(\mathrm{h}^{-1}\right)$ of $\mathrm{TiO}_{2} / \mathrm{MoS}_{2}$ composites of TM3, TM6, TM9, TM12 and $\mathrm{MoS}_{2}$ were calculated to be $0.005,0.003,0.010,0.004$ and $0.001 \mathrm{~h}^{-1}$, respectively. Obviously, TM9 shows the fastest decomposition rate for phenol among all the samples and no obvious self-degradation of phenol was observed.

To better elucidate the role of $\mathrm{MoS}_{2}$ on the generation and separation of photogenerated charge carriers, photocurrent measurements were carried out and compared. As shown in Fig. 4c, the TM9 heterostructure exhibits higher photocurrent density than that of pure $\mathrm{TiO}_{2}$ and $\mathrm{MoS}_{2}$, indicating the heterostructure is much more beneficial to promote effective charges transfer and easy electrons collection [15-20]. Cycling result in photodecomposition of phenol using TM9 photocatalyst is shown in Fig. 4d. It is clear that the TM9 shows the stable performance on the decomposition of phenol after 4 times usage, revealing the high stability of the composites. XRD pattern of the TM9 photocatalyst after recycling in Fig. S1 shows that no additional diffraction peaks were detected, indicating the high phase stability of photocatalyst during the cycling.

\section{Conclusion}

Multilayered $\mathrm{MoS}_{2}$ coated hollow $\mathrm{TiO}_{2}$ heterostructures were fabricated via a two-step hydrothermal method. XRD, SEM and TEM results confirmed the formation of $\mathrm{MoS}_{2} / \mathrm{TiO}_{2}$ heterostructures, which exhibited superior visible light photocatalytic activity towards photodegradation of phenol. The higher activity of heterostructures was attributed to improved light absorption and faster transfer of photoinduced charge carriers. The TM9 heterostructure also exhibited stable performance during recycling.

\section{Acknowledgments}

This work was supported by the National Science Foundation of Heilongjiang province (A2015005), the Outstanding Youth Science Foundation of Harbin Normal University (XKYQ201303), Innovative Talents Fund of Harbin (2014RFQXJ085).

\section{References}

[1] Schneider J, Matsuoka M, Takeuchi M, Zhang, JL, Horiuchi Y, Anpo M, Bahnemann, DW. Chem. Rev., 2014, 114: 9919-9986.

[2] Zhao YB, Chen QF, Pan F, Li Hui, Xu GQ, Chen W. Chem. Eur. J. 2014;20:1-7.

[3] Cui JJ, Ge YK, Chen SW, Zhao HS, Liu H, Huang ZH, Jiang HD, Chen J. J. Mater. Chem. B 2013;1:2072-2077.

[4] Yin HY, Wang XL, Wang L, Nie QL, Zhao HT, J. Alloys. Comp. 2015;640:68-74.

[5] Yin HY, Wang XL, Nie QL, Zhang Y, Yuan QL, Wu WW, J. Alloys. Comp. 2016;657:44-52.

[6] Zhou WJ, Yin ZY, Du YP, Huang X, Zeng ZY, Fan ZX, Liu H, Wang JY, Zhang H. Small 2013;1:140-147.

[7] Qi Y, Luan M, Wang G, Tan L, Li J. Appl. Surf. Sci. 2014;293:359-365.

[8] Liu CG, Wang LL, Tang YH, Luo SL, Liu YT, Zhang SQ, Zeng YX, Xu Y. Appl. Catal. B: Environ. 2015;164:1-9.

[9] Yang HG, Zeng HC, J. Phys. Chem. B 2004; 108: 3492-3495.

[10] Yang HG, Zeng HC, J. Phys. Chem. B 2004;11:108.

[11] Yan CG, Federico Rosei, New J. Chem. 2014;38:1883-1904.

[12] Tsai MC, Lee JY, Chen PC, Chang YW, Chang YC, Yang MH, Chiu HT, IN, Lee TK, Lee CY. Appl. Catal. B: Environ. 2014;147:499- 507. 
[13] Lu MX, Shao CL, Wang KX, Lu N, Zhang X, Zhang P, Zhang MY, Li XH, Liu YC. ACS Appl. Mater. Interfaces 2014;6:9004-9012.

[14] Hu KH, Huang F, Hu XG, Xu YF, Zhou YQ. Tribol. Lett. 2011;43:77-87.

[15] Hu KH, Hu XG. Mater. Sci. Technol. 2009; 25:407.

[16] Yin HY, Wang XL, Wang L, Nie QL, Zhang Y, Wu WW, Mater. Res. Bull., 2015; 72: 176-183.

[17] Huang HW, He Y, Li XW, Li M, Zeng C, Dong F, Du X, Zhang TR, Zhang YH, J. Mater. Chem. A, 2015;3: 24547-24556.

[18] Huang HW, Han X, Li XW, Wang SC, Paul K. Chu, Zhang YH, ACS Applied Materials \& Interfaces. 2015; 7:482-492.

[19] Behzad Pourabbas, Babak Jamshidi. Chem.Engin. J. 2008; 138: 55-62.

[20] Wingkei Ho, Jimmy C. Yu, Lin J, Yu JG, Puishan Li. Langmuir 2004; 20: 5865-5869.

\section{Figure Captions}

Fig. 1. XRD patterns of pure $\mathrm{TiO}_{2}$, pure $\mathrm{MoS}_{2}$ and $\mathrm{MoS}_{2} / \mathrm{TiO}_{2}$ heterostructures.

Fig. 2. SEM images of (a) pure $\mathrm{TiO}_{2}$, (b) pure $\mathrm{MoS}_{2}$, (c) TM3, (d) TM6, (e) TM9 and (f) TM12.

Fig. 3. Low-magnification TEM images of (a) TM9, (b) an enlarged view, (c) HRTEM images of the selected area from the rectangle of (b), and (d) the selected area electron diffraction patterns.

Fig. 4. (a) UV-vis DRS of pure $\mathrm{TiO}_{2}, \mathrm{MoS}_{2}$, and $\mathrm{TiO}_{2} / \mathrm{MoS}_{2}$ heterostructures. (b) Photodegradation of phenol over $\mathrm{TiO}_{2} / \mathrm{MoS}_{2}$ heterostructures, $\mathrm{TiO}_{2}$ hollow balls and $\mathrm{MoS}_{2}$ nanoplates. (c) Transient photocurrent responses of TM9 and pure $\mathrm{TiO}_{2}$ under simulated sun light irradiation. (d) Cycling test in photocatalytic decomposition of phenol using TM9 photocatalyst for 4 times. 


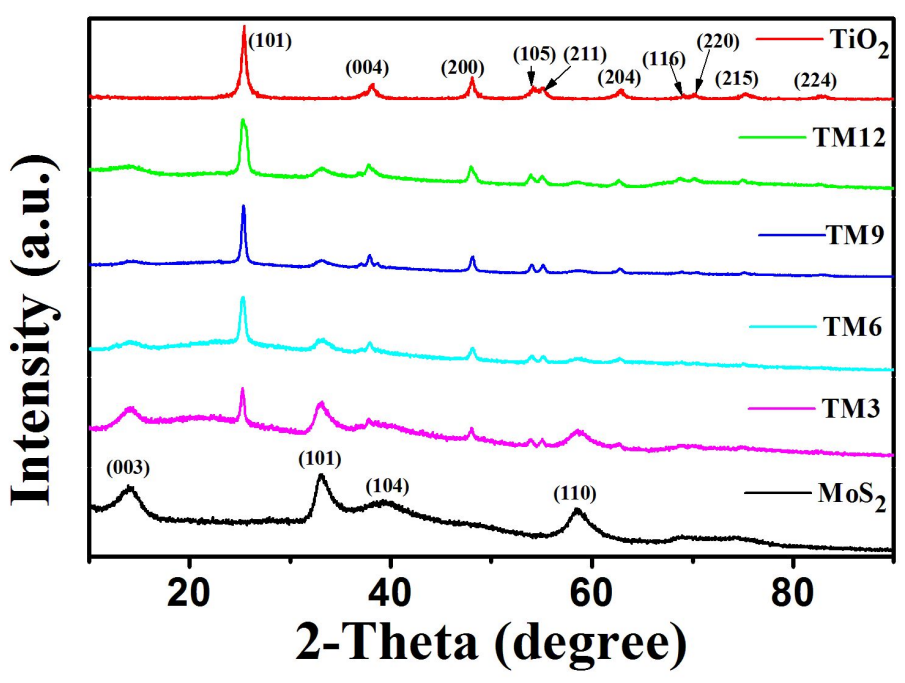



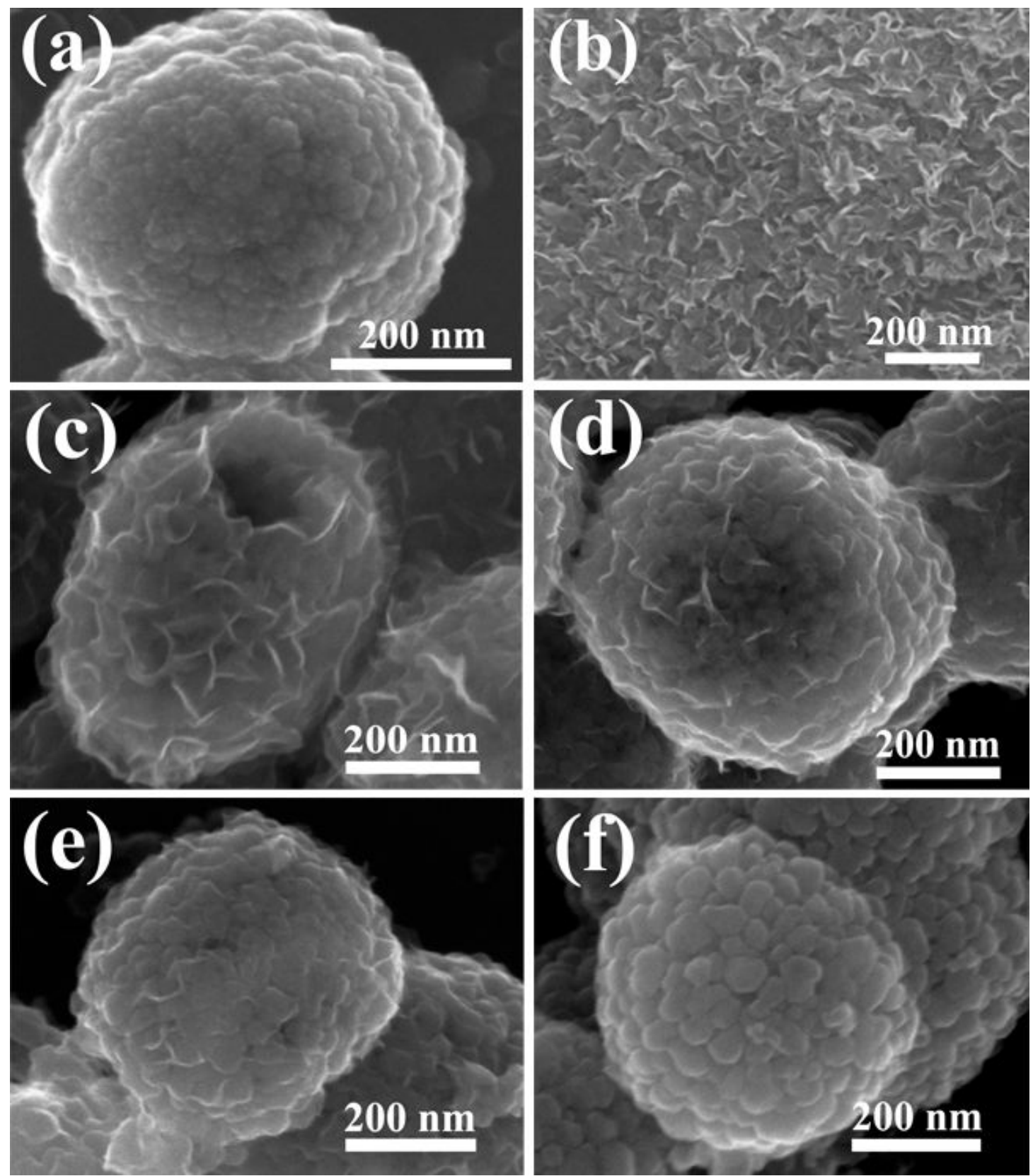


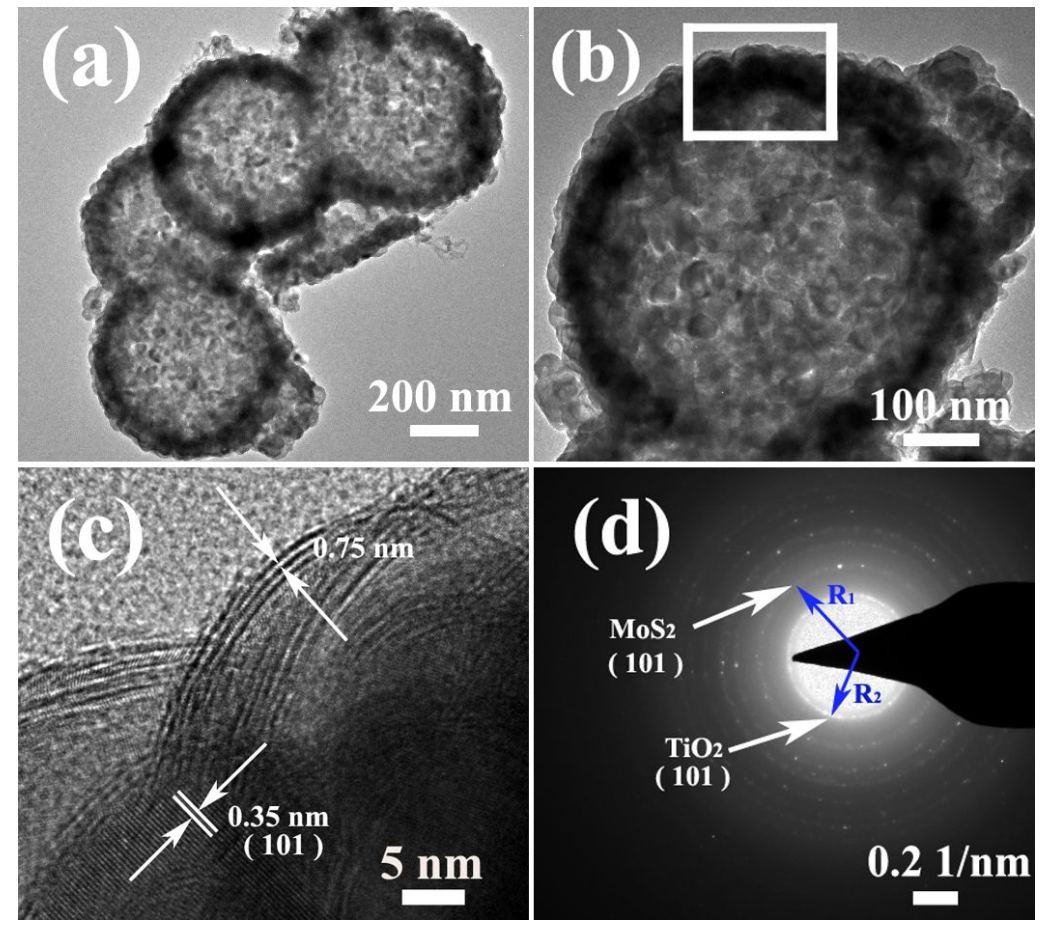



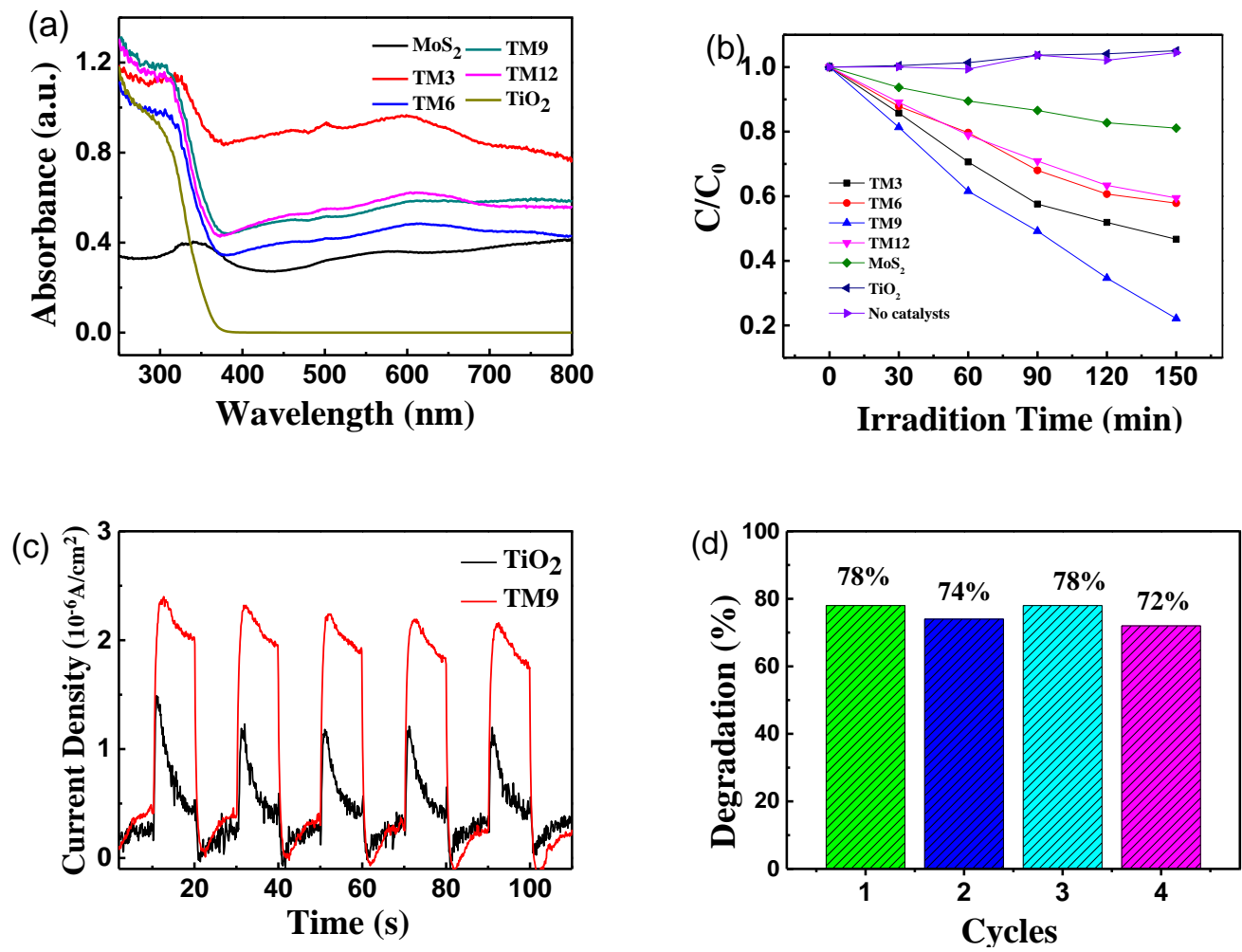